\title{
UTILIZAÇÃO DE WEBQUESTS NA FORMA DE BLOG COMO FERRAMENTA DE APRENDIZAGEM NA DISCIPLINA CIÊNCIA DOS MATERIAIS
}

\author{
Fábio Edenei Mainginski* \\ Luis Maurício Martins de Resende** \\ Adriane de Lima Penteado***
}

RESUMO: Esta pesquisa visa apresentar uma ferramenta metodológica utilizada no ensino de engenharia, como uma proposta do Programa de Mestrado em Ensino de Ciência e Tecnologia do campus Ponta Grossa, da Universidade Tecnológica Federal do Paraná. A ferramenta utilizada foi a webquest, considerada uma metodologia para organizar o processo de ensino utilizando recursos da internet, o que auxilia os estudantes na construção do conhecimento em um ambiente de aprendizagem. Tal metodologia foi aplicada aos estudantes da disciplina Ciência dos Materiais dos cursos de Engenharia em Controle e Automação e Engenharia Mecânica. O referencial teórico que embasou o trabalho foi construído pelos estudos de David Ausubel sobre aprendizagem significativa, bem como pelas Tecnologias da Informação e Comunicação na Educação (TICs). A conclusão que pode ser obtida com a utilização dessa junção de ferramentas (webquest e blog) é que quando os meios interativos aliam-se ao processo de ensino, há o enriquecimento da aprendizagem do aluno. $\mathrm{O}$ fato de a informação ficar disponibilizada o tempo todo aumenta a possibilidade de intervenções. Os aspectos de interação social, reintegração do aluno às aulas e ativador da curiosidade foram os pontos positivos apontados pelos alunos.

Palavras-chave: Blog, Webquest, Ciência dos Materiais, Metodologia de Ensino, Ensino de Engenharia.

\section{USING BLOGS AS A LEARNING TOOL IN THE MATERIALS SCIENCE COURSE}

ABSTRACT: This research aims to present a methodological tool used in engineering education, as a proposal of the Masters Program in Teaching of Science and Technology at Universidade Tecnológica Federal do Paraná - campus Ponta Grossa. The tool used was the webquest, considered a methodology to organize the process of teaching using Internet resources, which assists students in constructing knowledge in a learning environment, and has been applied to students of the Materials Science course for both Control and Automation Engineering and Mechanical Engineering degrees of the institution. The theoretical work that based this research was built by David Ausubel's studies on meaningful learning, and by the Information and Communication Technologies in Education (ICT). The conclusion reached with the use of joint tools (webquest and blog) is that when interactive media are allied to the teaching process, the learning process is enriched, because such information is available all the time, rising the possibility of interventions. Aspects such as social interaction, reintegration of students to classes and curiosity activation were the positive aspects mentioned by students.

Keywords: Blog, webquest, Materials Science, Teaching Methodology, Engineering Teaching.

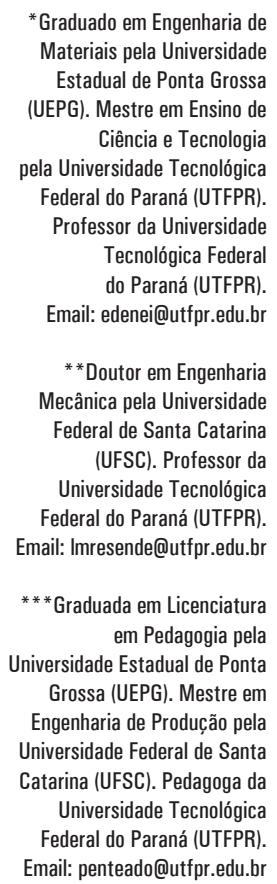




\section{INTRODUĈ̣̃O}

As pesquisas sobre a construção do conhecimento e da aprendizagem na área de Ciências são objeto de estudo de vários autores que visam estabelecer um referencial teórico-empírico para conduzir suas discussões acerca do tema.

A perspectiva que coloca o aluno agente ativo do conhecimento é abordada pelo Programa de Mestrado em Ensino de Ciência e Tecnologia da Universidade Tecnológica Federal do Paraná, que, entre outros objetivos, visa promover o estudo dos diferentes modelos que norteiam a elaboração do conhecimento científico considerando os contextos históricos e socioculturais nos quais esse conhecimento foi produzido e validado.

O estudo que norteia a ação principal do programa de mestrado é a vinculação da teoria estudada com o processo de ensino de uma instituição. Nesse sentido, buscou-se implementar ações de inovação metodológica na disciplina de Ciência dos Materiais dos Cursos de Engenharia ofertados no campus Ponta Grossa da Universidade Tecnológica Federal do Paraná, tendo como proposta utilização de blogs educativos.

Este trabalho está centrado nas teorias de aprendizagem e também na utilização de Tecnologias de Informação e Comunicação (TIC $\underline{\text { s }}$ na educação, situando-se em um espaço de reflexão sobre o uso dessas novas abordagens didáticas utilizando-se de situações empíricas de utilização das TICs, em particular de ambientes amparados na internet.

A disciplina, que é o foco deste trabalho, é denominada de Ciência dos Materiais e investiga as relações existentes entre as estruturas (atômicas, microscópicas e macroscópicas) e as propriedades (mecânica, elétrica, térmica, magnética, ótica e deteriorativa) dos materiais (CALLISTER, 2002).

Nas últimas décadas, a área dos materiais, bem como suas bases científicas e tecnológicas, tornou-se um campo de estudo de toda a comunidade acadêmica, surgindo na forma de uma área de estudo do Conselho Nacional de Desenvolvimento Científico e Tecnológico (CNPq). A grande quantidade de pesquisas voltadas às inovações científicas e tecnológicas traz uma evolução rápida dos conceitos dessa natureza. Uma disciplina escolar não suporta essa transformação de conceitos com grande velocidade, principalmente uma disciplina introdutória como Ciência dos Materiais (CM).

Nesse cenário, tanto os professores e profissionais da área, por meio de comentários realizados no ambiente escolar, quanto os estudantes, concordam sobre a importância da disciplina de CM, mas, mesmo assim, existe a falta de motivação necessária para um melhor rendimento dos alunos na disciplina, o que, por consequência, leva a um grande índice de reprovação e desistência, fato verificado por meio de acompanhamento de desempenho acadêmico.

A preocupação com uma inovação metodológica que despertasse maior curiosidade dos estudantes, e que promovesse uma diminuição dos índices de evasão e repetência foram os principais motivadores para a realização deste trabalho. 


\section{REVISÃO DE LITERATURA}

\section{Aprendizagem Significativa}

O psicólogo americano David Paul Ausubel contribuiu para a educação ao descrever a teoria da aprendizagem significativa. Para ter significado, o processo de ensino necessita fazer algum sentido para o aluno e, nesse processo, a informação deverá interagir e ancorar-se nos conceitos relevantes já existentes na estrutura do aluno.

Para Ausubel, a aprendizagem significativa se verifica quando o banco de informações no plano mental do aluno se revela, através da aprendizagem por descoberta e por recepção. No entanto, segundo Martin \& Solé in Coll (2004, p. 61):

\section{Ausubel chama a atenção para um erro que se produz em muitos casos quando se con- sidera que as aprendizagens significativas só podem ocorrer em situações de descobertas e que uma tarefa organizada mediante a exposição ao aluno de uma informação nova conduzirá necessariamente a uma aprendizagem mecânica ou repetitiva.}

$\mathrm{Na}$ visão de Ausubel, a aprendizagem significativa é preferível à aprendizagem mecânica ou memorística, por se constituir em um método eficiente e prático.

Pode-se salientar, ainda, que a teoria representada por Carl Rogers, denominada de corrente humanista não diretiva em educação, adotou o conceito de aprendizagem significativa ao levar em consideração os motivos que levam à aprendizagem.

Os princípios comuns à aprendizagem significativa, na visão de Ausubel, Rogers e Coll, embasam a teoria utilizada por muitos educadores nos dias atuais. O fundamento principal, comum às três visões, para Santos (2008, p.62), é o fato de necessitar que ocorra uma motivação de dentro para fora, por parte do indivíduo que aprende. Ausubel deixa claro que esse movimento de dentro para fora é essencial para desencadear a "ancoragem" dos conceitos (caso o que o aluno já saiba seja suficiente para receber o novo). Para Rogers, esse movimento é provocado pelo interesse em função de projetos pessoais, e, para Coll, está relacionado com a intenção de aprender. O que o provoca segundo Santos (2008, p.62), é um processo interno que pode ser compreendido como "fazer sentido". Seja para "ancorar", para causar interesse ou para desencadear a intenção de aprender, o objeto do conhecimento precisa, primeiramente, fazer sentido para o sujeito.

Dessa forma, chega-se à seguinte definição: a aprendizagem significativa é aquela que ocorre a partir do surgimento de um sentido pessoal por parte de quem aprende, o que desencadeia uma atitude proativa que tenta desvendar o novo e (re) construir conceitos que ampliam cada vez mais a habilidade de aprender.

Para Pozo (2002, p. 90), "a teoria de Ausubel prioriza a aprendizagem cognitiva, que é a integração do conteúdo aprendido numa edificação mental ordenada, a estrutura cognitiva". Desse modo, essa estrutura representa todo o conjunto de informações armazenado e organizado em qualquer modalidade do conheci- 
mento. Para ele, a interação de fatores prévios armazenados com novos fatores, provenientes de aprendizagens mais recentes, compõe a experiência cognitiva, que é mais bem construída com o uso de fatores externos de simpatia do aluno.

Nesse cenário de construção de experiências cognitivas, umas das alternativas que levam à aprendizagem significativa, com a adoção de fatores externos de simpatia do aluno, é representada pelas novas tecnologias de informação e de comunicação.

\section{Utilização das Tecnologias da Informaçã̃o e da Comunicação (TICs) no ensino de Ciências}

Charlot (2008, p. 21) afirma que "existe uma diferença entre informação' e 'saber': como usar as informações disponibilizadas pela internet para transmitir ou construir saberes?’. Para ele, a maioria das escolas apresenta forma e estrutura de espaço, de distribuição de alunos e de modos de avaliação que não condizem com o uso pedagógico das tecnologias da informação. Portanto, quando o professor encontra espaço na organização do ensino para utilização de novos modelos que forneçam melhores resultados, há a necessidade de enfrentar e vencer o desafio.

Um dos constantes desafios que os professores precisam enfrentar diz respeito à ocupação dos espaços de informação e comunicação que nascem e crescem a todo momento. Para Furió e Vilches apud Garcia-Milá (2004, p. 364), um dos objetivos do ensino de Ciências na atualidade é:

promover a aprendizagem entendida como uma atividade aberta e criativa em que a construção do conhecimento do aluno seja apresentada como um desafio, como uma 'aventura do pensamento com toda sua carga potencial e motivadora', cultivando, desse modo, a flexibilidade mental associada ao valor da tolerância em face de pontos de vistas opostos.

Para a autora supracitada, os teóricos de sua análise consideram a importância de introduzir e trabalhar tecnologia nas aulas de Ciências como uma via de privilegiada para desenvolver as atitudes positivas dos alunos em relação à ciência, argumentando que os projetos educacionais desenvolvidos nessa direção conseguiram efetivamente incrementar de forma significativa seu interesse pela ciência e melhorar a aprendizagem. (GARCIA-MILÁ, 2004, p. 365).

A utilização das novas tecnologias de informação e comunicação no ensino de Ciências tem um histórico recente no ambiente escolar. As primeiras iniciativas aconteceram nos Estados Unidos, com o surgimento do computador, há quase sessenta anos. Esse espaço de tempo é considerado recente se comparado ao surgimento das primeiras práticas de ensino na humanidade. Porém, a utilização das citadas tecnologias é um processo irreversível nos dias atuais, por fazer parte de um novo paradigma educacional.

Para Behrens (2005, p. 27), “o mundo eletrônico facilitou a comunicação e encurtou distâncias” e (idem, p. 37) “o desafio que se impõe é buscar a influência desse novo paradigma no processo educativo, nas propostas pedagógicas e no fazer docente". 
Sobre esse novo paradigma, Rezende (2002, p. 1) afirma que

\begin{abstract}
$\mathrm{Na}$ virada do século, não se trata mais de nos perguntarmos se devemos ou não introduzir as novas tecnologias da informação e da comunicação no processo educativo. Já na década de 80 , educadores preocupados com a questão consideraram inevitável que a informática invadisse a educação e a escola, assim como ela havia atingido toda a sociedade (Monteiro \& Rezende, 1993). Atualmente, professores de várias áreas reagem de maneira mais radical, reconhecendo que, se a educação e a escola não abrirem espaço para essas novas linguagens, elas poderão ter seus espaços definitivamente comprometidos (Kawamura, 1998).
\end{abstract}

Portanto, a utilização das novas tecnologias da comunicação e informação no ensino torna-se inevitável pelas exigências de configuração de um novo processo, que se inicia na escola e se concretiza na sociedade.

\title{
Tecnologias da Informação e da Comunicação (TICs) na educação: webquest e blog
}

A webquest pode ser considerada uma metodologia para organizar o processo de ensino utilizando recursos da internet, que auxilia os estudantes na construção do conhecimento em um ambiente de aprendizagem guiado.

A webquest é um formato de aula baseado na investigação orientada e em trabalhos cooperativos em que a maioria ou todas as informações com que os alunos trabalham vêm da web, e é uma metodologia que foi proposta por Bernie Dodge, em 1995. (DODGE, 1995). De acordo com o conceito original, as webquests são mais adequadas como atividades de grupo, embora seja possível imaginar contextos e atividades para a utilização individual. Para tentar contornar e amenizar algumas dificuldades e aumentar a praticidade, optou-se por utilizar um blog como plataforma para a publicação das webquests.

O termo weblog, conforme Amaral, Recuero \& Montardo (2009), foi primeiramente usado por Jorn Barger, em 1997, como refererência a um conjunto de sites que "colecionavam" e divulgavam links interessantes na web, surgindo o termo "web"+"log" (diário web), que foi usado por Jorn para descrever a atividade de "logging the web".

Utilizando uma blogquest, uma webquest adaptada para ser construída no ambiente de um blog, apresenta, conforme Weymar (2009), as seguintes características:

- Pode ser construída usando serviços gratuitos e básicos;

- Por ser um blog, seu conteúdo é facilmente publicável e editável;

- O autor não precisa conhecer linguagem HTML;

- Não requer o uso de programas de FTP;

- Pode usar os serviços de comentário do blog para aumentar a interação;

- Pode ser distribuída por rss;

- Podem ser colaborativas, usando essa possibilidade dos blogs.

Assim, a blogquest torna-se uma ótima opção como apoio ao ensino e à construção do conhecimento, pois propicia as habilidades de análise, pesquisa e síntese. 


\section{METODOLOGIA}

\section{Planejamento das atividades}

A metodologia adotada para a realização deste trabalho partiu da busca de uma ferramenta gratuita, de fácil utilização e acesso, que estivesse presente no dia a dia principalmente de alunos que utilizam a internet como meio de comunicação. Pelas condições de acessibilidade, a ferramenta escolhida foi o blog.

$\mathrm{Na}$ atividade realizada, cada postagem foi desenvolvida na forma de uma atividade de webquest, direcionada para a disciplina de Ciência dos Materiais. O período de utilização dessa ferramenta foi de cinco semanas, com cada atividade proposta para ser realizada no período de uma semana.

O primeiro passo da ferramenta foi a estruturação do ambiente do blog para receber as atividades, começando com a realização de uma análise em alguns servidores gratuitos de serviços de hospedagem e edição de blogs. Como resultado da análise, optou-se pelo servidor EDUBLOGS.ORG (http:/ /www.edublogs. org), devido às ferramentas disponíveis, facilidade na criação, na atualização e nas possibilidades de administração do blog e, ainda, por possuir gratuidade. Esse servidor é estruturado para blogs educativos, possuindo suporte para conteúdo multimídia (podcasting, fotos e vídeos), sendo o acesso e a administração facilitados por ferramentas de passo a passo, dicas e tutoriais.

$\mathrm{Na}$ sequência da atividade, foi criado e estruturado o blog - Ciência e Tecnologia dos Materiais, com o endereço http://ctecmat.edublogs.org, para receber postagens na forma de webquests.

Em sua estruturação, foram criadas subdivisões ,sendo uma página para descrever os objetivos do blog, incluindo a descrição sobre a ferramenta de webquest. Uma segunda página foi criada para servir de acompanhamento para os alunos, mostrando as avaliações parciais de cad um. Utilizou-se uma outra página para receber as postagens, comentários e respostas das atividades a serem realizadas. Essa estrutura está mostrada na figura 1. A estrutura das webquests seguiu da mesma estrutura sequencial de postagens utilizada em blogs. Assim, os comentários ficaram vinculados às postagens.

Figura 1: Estrutura de páginas do blog.

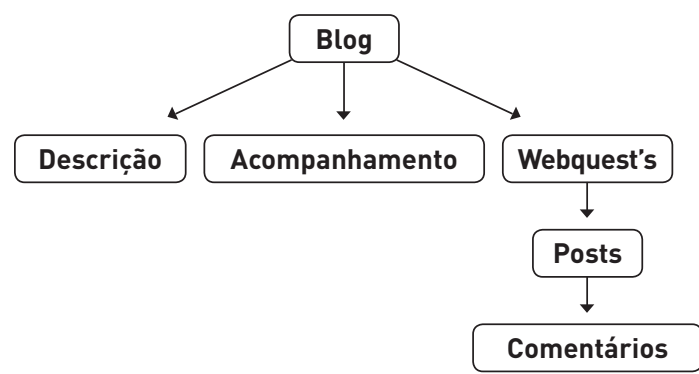

O passo seguinte foi dividir o conteúdo da disciplina em cinco partes. Foram planejadas atividades de webquest para cada etapa, com intervalos de uma se- 
mana, podendo classificar essas atividades como webquests curtas (DODGE, 1995).

O ambiente foi utilizado por estudantes da disciplina de Ciência dos Materiais, no Curso de Engenharia Mecânica e Engenheria de Controle e Automação. As atividades foram desenvolvidas pelos alunos que já haviam passado por uma avaliação escrita e tradicional, com o objetivo de promover uma recuperação do conteúdo que eles não conseguiram alcançar na totalidade, fazendo com que revisassem esses conteúdos já ministrados e, através de atividades interativas, buscassem a leitura e posterior assimilação dos conceitos científicos relacionados ao tema.

\section{Webquests}

A ferramenta de blog apresenta-se favorável ao uso de webquests por permitir ao professor verificar o desenvolvimento do aprendizado do aluno, mesmo não estando junto com ele no momento da realização das atividades.

Assim, cada atividade de webquest foi planejada para assegurar que os conceitos científicos relacionados àquele conteúdo fossem assimilados pelo aluno seguindo os objetivos listados no Quadro 1.

Após a publicação de cada etapa, coube aos alunos realizar as atividades propostas, bem como encontrar uma maneira para resolver os problemas por meio de interações entre eles, registrando seus comentários e suas buscas pela rede, resultando em um apanhado de recursos e endereços visitados pelos alunos.

Quadro 1: Objetivos das atividades de webquests realizadas.

\begin{tabular}{|l|l|l|l|}
\hline ETAPA & CONTEÚDO & TERMOS / CONCEITOS & OBJETIVOS A ATINGIR COM A WEBQUEST \\
\hline $\mathbf{1}$ & $\begin{array}{l}\text { Estrutura } \\
\text { do Átomo }\end{array}$ & $\begin{array}{l}\text { Átomo, Elétron, Próton, } \\
\text { Nêutron, Elétron de Valência, } \\
\text { Modelo Atômico }\end{array}$ & $\begin{array}{l}\text { Reforçar os conceitos de química geral } \\
\text { pertinentes à estrutura dos átomos. }\end{array}$ \\
\hline $\mathbf{2}$ & $\begin{array}{l}\text { Ligação } \\
\text { Química }\end{array}$ & $\begin{array}{l}\text { Tabela Periódica, Moléculas, } \\
\text { Ligação Covalente, Ligação } \\
\text { lônica, Ligação Metálica, } \\
\text { Metal, Polimero, Cerâmica }\end{array}$ & $\begin{array}{l}\text { Conhecer e entender as características } \\
\text { dos 3 tipos mais importantes de ligações } \\
\text { primárias, bem como conhecer as } \\
\text { características dos 3 tipos de materiais. }\end{array}$ \\
\hline $\mathbf{3}$ & $\begin{array}{l}\text { Arranjo } \\
\text { Atômico }\end{array}$ & $\begin{array}{l}\text { Cristal, Amorfo, Grão, } \\
\text { Alotropia, Isotropia, } \\
\text { Anisotropia, Célula Unitária, } \\
\text { Fator de Empacotamento } \\
\text { Atômico }\end{array}$ & $\begin{array}{l}\text { Identificar os modelos de ordenação atômica } \\
\text { encontrados em alguns dos metais mais } \\
\text { comuns, e saber que muitos dos sólidos } \\
\text { podem ter alterado o seu arranjo atômico } \\
\text { como resultado de variações de temperatura } \\
\text { e/ou pressão. }\end{array}$ \\
\hline $\mathbf{4}$ & $\begin{array}{l}\text { Imperfeições } \\
\text { Cristalinas }\end{array}$ & $\begin{array}{l}\text { Liga, Solução Sólida, } \\
\text { Interstício, Discordância, } \\
\text { Contorno de Grão, Microscopia }\end{array}$ & $\begin{array}{l}\text { Reconhecer a importância das imperfeições } \\
\text { cristalinas e diferenciar entre os tipos } \\
\text { básicos e, ainda, familiarizar-se com o } \\
\text { funcionamento básico de um microscópio. }\end{array}$ \\
\hline $\mathbf{5}$ & $\begin{array}{l}\text { Propriedades } \\
\text { Mecânicas }\end{array}$ & $\begin{array}{l}\text { Módulo de Elasticidade, } \\
\text { Tensão de Escoamento, } \\
\text { Tensão Máxima, Tensão } \\
\text { de Ruptura, Dureza, } \\
\text { Ductilidade, Fragilidade, } \\
\text { Resiliência, Tenacidade, } \\
\text { Rigidez, Dúctil, Frágil }\end{array}$ & $\begin{array}{l}\text { Aprender as relações existentes entre algumas } \\
\text { propriedades mecânicas dos materiais e } \\
\text { realizar a leitura de valores após construir um } \\
\text { gráfico de Tensão vs. Deformação. }\end{array}$ \\
\hline
\end{tabular}


Ao término de cada etapa, era necessário que o aluno encaminhasse, por e-mail, um documento sintetizando as atividades solicitadas na webquest, para que fossem avaliadas as suas conclusões, que deveriam estar baseadas nos comentários originados no blog. Além disso, seria avaliada a interação que tiveram com o blog, sendo o parâmetro principal as contribuições nos comentários.

Inicialmente, a avaliação das atividades realizadas no blog foi pouco profunda, pois o objetivo inicial estava voltado para o desenvolvimento operacional do ambiente, bem como para a familiarização do professor com o mesmo.

Nas semanas que se seguiram, os alunos verificavam as atividades disponíveis no blog e também compareciam para as aulas presenciais, intercalando, dessa maneira, o acesso às atividades on-line e os conteúdos das aulas presenciais.

Nesses encontros, os alunos desenvolveram as atividades propostas para aquela etapa. O acompanhamento de participação foi realizado pelo professor por meio do número de visitas e de comentários que foram deixados no blog. Evidentemente, a análise crítica dos teores dos comentários também explicitaram o envolvimento dos alunos com o conteúdo da disciplina.

\section{RESULTADOS E AVALIAC̣ÃO DA FERRAMENTA}

Ao final da realização das atividades, foi proposta a aplicação de um instrumento de avaliação de uso das atividades e lições na forma de webquest, disposta no blog da disciplina. Para isso, foi criado um questionário on-line, utilizando-se das ferramentas de formulário do Google Docs. O formulário que foi respondido pelos alunos está disponível no endereço: <https://spreadsheets.google.com/vie wform?hl=en\&formkey $=$ cnBfbnFSWGxJa1Nxc05FNy03YVF0c0E6MA..>

Para dispor dos dados obtidos no instrumento de avaliação, foi elaborada uma matriz de categorias para agrupar os itens estudados. Fizeram parte da análise cinco itens agrupados nas categorias relacionadas a seguir:

$1^{\text {a }}$ categoria - Perfil de acesso: como as atividades realizadas nos três cursos são compatíveis entre si, todos os alunos responderam ao mesmo questionário. A primeira parte do questionário pretendia dar uma noção do perfil e da maneira como os alunos realizaram as atividades propostas. Para isso, foi investigado o tempo de dedicação, por semana, com as atividades de webquest. A maioria dos alunos, 58\%, disseram haver dedicado de três a seis horas semanais para a atividade, enquanto $38 \%$ afirmaram ter dedicado entre sete e dez horas por semana.

$2^{\text {a }}$ categoria - Uso da ferramenta: a investigação sobre a possibilidade de se utilizar, na visão do aluno, as atividades de webquest, durante todas as aulas, é a questão principal dessa categoria. Pelas respostas obtidas é possível perceber que uma diferença inexpressiva indica que, na visão do aluno, não se poderia utilizar essa ferramenta como recurso único de aprendizagem de toda a disciplina.

$3^{\text {a }}$ categoria - Visão do aluno: Na questão que solicitou que os alunos relatassem sobre sua impressão em relação à atividade de webquest realizada, com a 
possibilidade de incluírem sugestões e comentários, foi relatado que a atividade foi aceita pela totalidade dos alunos participantes; promove consciência em relação ao meio ambiente, com a economia de papel; permite melhor organização das informações; exige muita pesquisa, o que leva a um estilo interessante de aprender; oferece boa oportunidade de recuperação de conteúdos; faz o aluno ter mais esforço; promove a inclusão do aluno que acreditava que não teria mais oportunidade de aprendizado.

$4^{\mathrm{a}}$ categoria - Mapa conceitual: na webquest final foi solicitado que os estudantes construíssem individualmente um mapa conceitual para representar graficamente as relações estabelecidas entre os conceitos construídos e estudados. A atividade realizada permitiu que os estudantes, segundo suas próprias considerações, organizassem os conceitos de maneira objetiva, acompanhassem o aprendizado e avaliassem o rendimento. Assim, os comentários mais comuns foram de que o mapa conceitual facilita o estudo, pois organiza de maneira visual o conteúdo.

$5^{\text {a }}$ categoria - Dificuldades: tendo em vista a necessidade e a curiosidade em saber em que etapa da disciplina de Ciência dos Materiais os alunos têm maior dificuldade, solicitou-se que eles marcassem até três capítulos do livro-texto nos quais encontraram maior dificuldade em entender o conteúdo. Essa pergunta está relacionada à necessidade que o professor possui em definir em que etapa, durante o semestre, devem ser utilizadas as atividades como forma de fortalecer o entendimento do conteúdo e, também, como forma de amparar o aluno na compreensão de conceitos importantes. Nas respostas obtidas, percebe-se que os capítulos sobre Difusão e Diagrama de Fases são os que, para a maioria, representam maior dificuldade.

\section{CONSIDERACְ̃̃ES FINAIS}

A análise do tema proposto se apoia nos argumentos teóricos do campo de estudo da estrutura cognitiva, e tem a aprendizagem significativa como concepção norteadora, e Ausubel como o autor de suas mais evidentes ideias.

Ao buscar a interface entre as ideias de Ausubel e a proposta de trabalho que pretendeu utilizar webquests na forma de blog como ferramenta de aprendizagem na disciplina Ciência dos Materiais, concluímos que se em uma atividade de pesquisa na internet o aluno pode facilmente perder o foco do que está pesquisando, dificultando a sua interação com o ambiente e com os demais alunos e professor, fato que Ausubel denomina de interferência de fator externo, com a atividade de webquest esse fator não interrompe a aprendizagem.

$A$ atividade de webquest faz com que o aluno tenha um caminho a ser percorrido, através das tarefas propostas. Evidentemente, ele pode fazer seu próprio caminho de pesquisa, mas acaba sempre retornando ao tema original devido às atividades estarem focadas e com um objetivo de aprendizado bem definido. Esse fator de isolar a distração e permitir que haja continuidade na atividade, leva, segundo Ausubel, à aprendizagem significativa. 
A estratégia mista, que neste trabalho é entendida como sendo realizada por meio da intercalação de aulas expositivas e atividades em ambientes virtuais, deve ser encarada como uma alternativa para melhorar o rendimento dos alunos. Para Pozo (2002, p. 127), de acordo com Ausubel, Novak e Hanesian, “a organização do material, vocabulário e terminologias adequados a aluno, conhecimentos prévios sobre o tema e predisposição favorável para a compreensão leva à busca do significado e sentido do que se aprende"

Para uma evolução da ferramenta, já se tem definida a implantação dessa metodologia de maneira a apresentar atividades regulares na disciplina de Ciência dos Materiais, ministrada nos cursos de Engenharia do campus Ponta Grossa, da Universidade Tecnológica Federal do Paraná.

A impressão que se tem é que o trabalho sempre está inacabado, precisando de atualização ou aperfeiçoamento ou, ainda, somente uma formatação diferente. Desse modo, a metodologia está sempre sendo atualizada pelo professor, tornando-se uma ferramenta ajustável às necessidades de cada disciplina, bem como de cada professor.

Assim, pode-se perceber que o processo educacional está em constante mudança. Discussões estão ocorrendo pelo mundo. Em nosso país, há a implantação de uma nova legislação, incorporando, no cotidiano escolar, as novas tecnologias digitais de comunicação. Para tanto, deseja-se que em um futuro próximo essas metodologias ligadas à TIC façam parte de todos os currículos dos cursos de Engenharia e graduações em geral.

\section{REFERÊNCIAS BIBLIOGRÁFICAS}

AMARAL, Adriana; RECUERO, Raquel; MONTARDO, Sandra (orgs.). Blogs.Com: estudos sobre blogs e comunicação. São Paulo: Momento Editorial, 2009.

GARCIA-MILÁ, Mercé. O ensino e a aprendizagem das ciências físico-naturais: uma perspectiva psicológica. In: ---- COLL, Cesar; MARCHESI, Álvaro; PALACIOS, Jesús. Desenvolvimento psicológico e educação: Psicologia da educação escolar. Vol. 2. Porto Alegre: Artmed, 2004.

BEHRENS, Marilda Aparecida. O paradigma emergente e a prática pedagógica. Petrópolis: Vozes, 2005. CHARLOT, Bernard. O professor na sociedade contemporânea: um trabalhador na contradição. Revista da FAEEBA - Educação e contemporaneidade. Salvador: v. 17, n. 30, p. 17-31, jul/dez. 2008.

CALLISTER JR., William D. Ciência e engenharia de materiais: uma introdução. 5. ed. Rio de Janeiro: LTC, c2002. COLL, Cesar; MARCHESI, Álvaro e PALACIOS, Jesús. Desenvolvimento psicológico e educação: Psicologia da educação escolar. Vol. 2. Porto Alegre: Artmed, 2004.

DODGE, B. Webquest: uma técnica para aprendizagem na rede internet. The Distance Educator, V.1, no 2, 1995.

MARTIN, Elena; SOLÉ, Isabel. Aprendizagem significativa e a teoria da assimilação. In: COLL, Cesar; MARCHESI, Álvaro e PALACIOS, Jesús. Desenvolvimento psicológico e educação: Psicologia da educação escolar. Vol. 2. Porto Alegre: Artmed, 2004.

POZO, Juan Ignacio. Aprendizes e mestres: a nova cultura de aprendizagem. Porto Alegre: Artemed, 2002. REZENDE, Flávia. ENSAIO. As novas tecnologias na prática pedagógica sob a perspectiva construtivista. Revista Ensaio Pesquisa em Educação em Ciências. Belo Horizonte, volume 02, número 01, p.75-98, março 2002. 
SANTOS, J. C. F. Aprendizagem significativa: modalidades de aprendizagem e o papel do professor. Porto Alegre: Mediação, 2008.

SILVA, José Carlos Tavares da. Um modelo para avaliação de aprendizagem no uso de ferramentas síncronas em ensino mediado pela WEB. Orientador: Bruno Feijó. 2004181 f. Tese (Doutorado) - Departamento de Informática, Pontifícia Universidade Católica do Rio de Janeiro (PUC_RJ), Rio de Janeiro, 2004. WEYMAR, R. R. Webquest, Blogquest: Ferramentas para Pesquisa Web. In: SIMPÓSIO INTERNACIONAL, 3. ; FÓRUM NACIONAL DE EDUCAÇÃO, 6., 2009, Canoas/RS. Anais... Canoas: ULBRA, 2009

Data de Recebimento: 20/03/2011

Data de Aprovação: 08/10/2011

Data da Versão Final: 20/04/2012 